\title{
The Peculiarities of the Traditional Societies and Non-Traditional Societies and Their Transformation
}

\author{
Urunova Hamida Umarboevna ${ }^{1}$, Zohidov Ochil ${ }^{2}$ \\ ${ }^{1}$ Candidate of pedagogical sciences, Chair of social sciences \\ Institute of Economy and Trade of Tajik State University of Commerce \\ ${ }^{2}$ Th edoctor of philosophy, Chair of Social sciences, Tajik State University of Law, Business and Policy
}

\begin{abstract}
The article analyses the peculiarities of the traditional and non-traditional societies and the process of their transformation. The author of the article emphasizes that the peculiarities of the mentality of the national communities depend on their historical and cultural specification and that the level of social-cultural development depends on the life style, the system of values and the psychological peculiarities of the nation. Therefore she considers that it is necessary to make a comparative analysis of the spiritual cultures of both traditional and non-traditional societies and to assist in saving the stereotypes of thinking and behavior of the people which have a perspective and uniting character. Also she thinks that it is important to identify those elements which should be corrected and borrow from the non-traditional societies those elements which can promote modernization of the traditional society.
\end{abstract}

Keywords: traditional society, non-traditional society, transformation, modernity, traditionalism, liberalism, postmodernity. 


\section{Introduction.}

It is necessary to mention that from the last 2 decades the process of interconnection of all spheres of human life have been global as an integral part of modern civilization. It goes without saying that the ontological premises of the process of globalization are based on material roots of human life which started from the second half of the XXth century. Wherein the scientific-technological progress has become the basic reason of increasing the productive, technological, military potential of humanity and the reason of all global problems. It goes without saying that the modern process of globalization cause the problem of clash of cultures in the traditional societies as here we can see the problem of contradiction of cultures. Such confirmation is quite acceptable towards the cultures (especially the spiritual culture) of the postsoviet states, in particular Tajikistan republic, where traditionalism and mental features are brightly expressed. The peculiarities of the mentality of the national communities depend on their historical and cultural specification. The level of social-cultural development depends on the life style, the system of values and the psychological peculiarities of that nation. Therefore, we consider that it is necessary to make a comparative analysis of the spiritual cultures of both traditional and non-traditional societies and to assist in saving the stereotypes of thinking and behavior of the people which have a perspective and uniting character. Also we think it is important to identify those elements which should be corrected and borrow from the nontraditional societies those elements which can promote modernization of the traditional society.

\section{Traditional society.}

Firstly for the system analysis it is important to give a definition of the term "traditional society". A traditional society is that one in which the traditional values, customs dominate which regulate the people's behavior. The traditional society is defined by a strict gender hierarchy, sustainable stereotypes which determine the orientation and the system of values of the people of this culture. Mostly the Eastern countries are considered to be the traditional societies, which are characterized by the domination of the collectivistic interests over individualistic, traditionalism and unchangeableness of socio-cultural norms and orders. Traditional model of relationship supports more traditional norms of behavior without a critical analysis than the common sense. There is the atmosphere of the unquestioning 
following the traditional norms in the society where informal laws and rules have a great meaning. The society where traditionalism and public opinion have a ruling authority even ignores the power of the government. Traditionalism has a counterrevolutionary character. It is such a psychological condition of a person which does not accept innovational and reforming approach. A pressing power of traditionalism is able to annul any antitraditional action. But we cannot see only a negative picture in that society where traditionalism dictates its. According to the interpretation of some specialists traditionalism is such a life style which the wisdom of tradition is higher than intellect. But our experience shows that the not all traditional norms which function in Tajik society put wisdom of tradition higher than intellect. Just person's behavior in this framework conforms to the framework of the human intellect. High sense of hospitality, financial sacrifice for the sake of other people, a solidary relationship between neighbors, respecting family values, honoring an old generation and very many other examples can clearly show that morality is higher than everything and they are the elements of traditionalisms and a reasonable action. These values by the way have a uniting and a disciplining character. Actually traditionalism is very close to collectivism. Collectivism is such a model of social relationship where collectivistic interests are in the central attention but not personal. In the framework of the collectivistic model of relationship a person always tends to satisfy the social needs. According to the philosophical dictionary collectivism means:

"... supremacy of the collectivistic interests over personal. It recognizes the priority of the social benefit over personal and subordination of the personal interests to the social ${ }^{1}$ ".

Collectivism is also interpreted as a principle of mutual activity of people, their friendship Corporation, readiness to help, benevolence and others.

Having large families is one of the determinants of collectivism. According to the consumer economy and individualistic views large families are not supported, because baby takes much time, efforts and money. It demands a high level of sacrifice. Having large families is not the result of a high material development. It just emphasizes a high level of traditionalism and collectivism. In this case not personal principles, ambitions, or wishes

\footnotetext{
${ }^{1}$ Philosophy: Encyclopedia dictionary/ under the edition of A. A. Ivin. - Moscow: Gardarini, 2004.-1074p. http//www.ru.m.wikipedia.org (date of visit - 20.06.2016.)
} 


\section{SOCIAL SCIENCES IN THE 21ST CENTURY}

dominate but collectivistic one. Traditionalism and collectivism are two very sustainable characteristics of the traditional society which have a long history. These stereotypes of thinking and behavior of the people of the traditional society are rooted so much that can difficultly be modified or transformed. It can easily be shown in everyday life of Tajik people who in spite of their low level of life and prohibitions of the government anyway try to follow their traditions. Breaking old traditions is a very painful and difficult process, which shows its being fundamental. But as a western researcher Parsons T. mentions different cultures have a different orientation towards collective.

"No one culture demands a complete subordination of the personal interests to the interests of a collective ${ }^{2}$."

Other western researchers Herd Hofstede, Harry Triandis and Swartz developed an individualistic theory, which accents on minimal level of responsibility of an individual before the society ${ }^{3}$. According to their theory the individualistic culture is directed to individual care, personal freedom and independence. As for the opposite model of relationship an individual can get a freedom only then when he follows all the traditional norms dictated by the community. Some analytics think that the theory is developed by the western researchers and is for the western style of life only and it does not conform to the eastern life style. They consider that copying a western life style would be a confusion as an individualistic theory is not compatible with the eastern collectivistic culture. But my comparative analysis has shown me that our eastern culture needs such elements of the western culture like pragmatism, tendency to independence and freedom not harming our moral values.

According to the result of the research of the professor of Cornel university W. Bronfenbrenner family and collective are 2 fundamental elements of socialization of human being which help to transfer cultural values, educate a young generation, teach humanism,

\footnotetext{
${ }^{2}$ Bleher L. I., Lubarsky G. U. The main Russian argue: from westerners and Slavophiles to globalism and new middle ages. Chapter «Community and collectivism», M.,2003 http//www.ru.m.wikipedia.org (date of visit -15.06.2016.)
}

${ }^{3}$ Chaldini R., Kenrik D., Neyrberg S. Social psychology. Understand yourself to understand others. In 2 chapters, S. Petersburg, 2002. p.77 


\section{SOCIAL SCIENCES IN THE 21ST CENTURY}

altruism and responsibility before people. ${ }^{4}$ He totally supports the concept of a Russian psychologist A. Makarenko who proves the great role of collective in forming collectivistic and humanistic values. As Etzioni A.confirms:

"It is impossible to develop the society without the balance of individualism and collectivism."

In our case even in Tajik collectivistic society at the result of social -economic transformation some individualistic approaches are born in the people's consciousness and behavior so that can show the balance of collectivism and individualism in the society. Such process of transformation has been activated especially after the collapse of the Soviet regime which caused the change of the people's ideals and orientation. We can bring some bright examples from the real life of Tajik society which show the changing process of the mentality of people after the collapse of the Soviet regime and developing a civil society and market economy. All these tendencies of socio-economic transformation cause developing such mental features as pragmatism, innovativeness, ability to show initiatives, creating ideas and others.

\section{Non-traditional society}

Going on with analysis I would like to identify the specific features of the non-traditional societies. As we have mentioned the regulator of the social relationship in the traditional societies are not private actions, but those one which people receive from other generations. i.e. traditions. But innovativeness, originality, constant changes are considered to be the basic features of the non-traditional societies. A representative of the non-traditional society believes in his abilities, appreciates independence and a personal initiation. He considers that tradition is something which is not created personally or a product of personal imagination, generally it is something which does not belong to him, but received from others beyond. For the mundane consciousness of the modern period the word "tradition" firstly is associated as something which has lost its newness and it is connected with the past. Till the New Time it

\footnotetext{
${ }^{4}$ Bonfenbrenner U. «Tow worlds-two childhoods». Children in USA and USSR, translated by Pilipovsky V., Moscow $1976 \mathrm{http} / /$ www.ru.m.wikipedia.org (date of visit -18.06.2016.)

${ }^{5}$ Etzioni A., New global architecture: the mechanisms of transmission// Public lectures, «Polit.ru», 04.04.2009 http//www.ru.m.wikipedia.org (date of visit -15.06.2016.)
} 
was something which contradicted to the development and symbolized a backwardness. If to have a look at the history of the French revolution the traditionalists such as J. De Mestr considers that the French revolution happened because of the tense rejection of tradition by the thinkers of the period of Renaissance. Thereby at the beginning of the XIXth century in the European culture an ambivalent relationship to tradition has been formed because the scientists' opinions about the meaning and the content of tradition were different. For example, in Hegel's conception tradition takes a very important place in the process of the global historical objectification of spirit. As for Marx tradition is interpreted as an expression of class and group interests as an integral part of ideology. Marx considers that tradition is the instrument of manipulation of people's mind. F. Nietzsche thinks that tradition is the basis of daily backwardness which blocks the way of developing a superman. I. Herder notes that from one hand tradition is the engine of the human history and from another it is a blocking factor to develop the critical thinking. But in the process of the mental development the relationship to tradition has become more and more negative due to the scientific and technological achievements. In Hanna Arendt's opinion in the period of modern the traditionalism has been fully exhausted as the logics of the industrial development demands the replacement of tradition by the orientation to universal rationality. This idea was expressed more distinctly by Max Weber who for the first time contrasted a traditional way and a rational way of social organization. Tradition and rationality as a dialectic pair in the continuum of the development are 2 world of values between which there is a pressure and contradiction. A person between these two systems of the values in the traditional society in comparison with non-traditional one becomes a marginal.

One of the advantages of the non-traditional society is that it supports the intellectual and social initiation not paying attention at the age. The next feature of the non-traditional society is that it provides people with an intellectual and spiritual independence. "Tradition" in the non-traditional society does not have so much "authority and dignity" as it has in the traditional society. As for the modern society it sees traditions in the background of the social changes and rational thinking, as people's consciousness has a dynamic character. If the initial meaning of the word "tradition" included a special respect of something which person got form ancestors the its further sense in the modern society has been lost and faced inflation. The non-traditional society shows an emancipation - liberation from social dependence and getting adequate rights and obligations. The emancipation of the individual intellect liberates 
person from compulsory and choiceless power of tradition, that what I want to realize in the traditional society. But the traditional society criticizes emancipation as it considers that it destroys all the frameworks which disciplines social relationship. The non-traditional society is based on liberal ideology which proclaims human rights and freedom as the highest value. I as the representative of the traditional society can support those aspects of liberalism which liberates person from social pressure and embarrassment of the traditions. Of course there are traditions which should be saved for having a strong future generation. The most important values of the liberal ideology are freedom of public speech, freedom of religion, supremacy of law, inviolability of the private property which have a very poor condition in the traditional society. Modern liberalism also maximally supports pluralism and development of the civil society. Liberal culture does not support being patient and tolerate those actions which contradict to the personal interests. If to look at the history of the transformation of the western mentality we can face the fact of its forming due to the historical events, e.g. the American war for independence causes the first nation in the world which designed its constitution on the basis of liberal state. Or The Great French revolution is a great transformational event in the social and political sphere in France which destroyed the old political order and absolute monarchy in the country and in September 1792 the first French republic was proclaimed as a republic of free and equal citizens under the slogan "freedom, equality and brotherhood". The American Revolution (1775-1788), the war of Great Britain against the revolutionists of 13 colonies. In 1812 the designers of the Spanish constitution for the first time used the word "liberal" to explain the supporters of the political movement. Thus beginning from the end of the XVIIIth century the process of transformation started in the western countries and liberalism has become one of the leading ideologies in all the European countries. Just here a negative relationship of the non-traditional societies to stereotypes and traditions was born as it is an alien product but not the result of the individual approach.

Also the non-traditional society is inclined to the consciousness behavior and relationship to the world and its people consider that following traditions is just showing a very poor level of intellect and consciousness. The western society due to its scientism and rationalism has achieved the highest level of development in all spheres of human life. People in the nontraditional society possess a logical and pragmatic thinking, but the people of the traditional society, according to the conception of Levi-Brule, possess prelogical thinking. In individual freedom and individual consciousness are in the "comfort space". «Comfort» for the 
individual consciousness in the non-traditional society is created by pluralism and absence of outside pressure. Due to this "comfort" modern non-traditional societies are considered to be the most developed, advanced one. But in order to save this position it should not break the framework of "modern". The most powerful western sociologists developed a theory according to which all the features of modernity (liberalism, civil society, freedom, democracy) in the western societies have been maximally realized. In Jurgen Habermas's opinion humanity should follow those democratic values which are developed by modernity. Western sociologists consider that modernity is an ideal which the whole humanity should follow. I consider that both traditional and non-traditional societies should be careful about developing modernity into postmodernity.

\section{What should be done}

The process of transformation of the western society naturally causes the transformation of the traditional society. But scientists' opinions about the necessity of transformation of the traditional society differ. For example, a Russian philosopher A. Dugin considers that it is very important to refuse the principles of the modern society and go back to the "golden time" of traditionalism. Another Russian sociologist A. Vishnevsky thinks that today the traditional society has no chance even if it is actively resisting. According to the sociological analysis of the professor A. Nazaretyan if we want to keep our society in the static position it is necessary to reduce the number of people in the world. Today it is very important to make a clear analysis of the process of transformation when the cultures are being mixed. Firstly the task of philosophers and sociologists is to define the essence of the sociocultural changes and their results. Also it is necessary to make a strong analysis of the "traditional values" and their role in the life of the traditional societies. The meaning and the practical value of the stereotypes of thinking and behavior of the traditional people should be identified instead of following them blindly. For a harmonic development of the society and getting a sense and a real pleasure from life the societies should be honest with themselves and rethink the stereotypes, correct them if necessary, also try to save those one which promote the building of a strong and healthy society and bringing up a strong future generation. 


\section{Acknowledgement}

I want to thanks my consultants Mr. Zohidov O. the doctor of philosophy for providing the background information and discussion, sharing ideas and fruitful communication of issues indicated in this article.

\section{Reference}

1. Birukova M.A. Globalization: integration and differentiation of cultures // Philosophical sciences, 2000. - № 4. - p. 33-42.

2. Bleher L. I., Lubarsky G. U. The main Russian argue: from westerners and Slavophiles to globalism and new middle ages. Chapter «Community and collectivism», M.,2003 http//www.ru.m.wikipedia.org (date of visit -15.06.2016.)

3. Bonfenbrenner U. «Two worlds-two childhoods». Children in USA and USSR, translated by Pilipovsky V., Moscow 1976 http//www.ru.m.wikipedia.org (date of visit -18.06.2016.)

4. Chaldini R., Kenrik D., Neyrberg S. Social psychology. Understand yourself to understand others. In 2 chapters, S. Petersburg, 2002. p.77

5. Etzioni A., New global architecture: the mechanisms of transmission// Public lectures, «Polit.ru», 04.04.2009 http//www.ru.m.wikipedia.org (date of visit -15.06.2016.)

6. Gubanov N.N. Mentality: the essence, regularity of forming, development and functioning inn the society. Autoabstarct of the diss. Of the doctor of philosophy. - M., 2014.

7. Kosichenko А.Г. National cultures in the process of globalization.// http://www.orda.kz. Electronic informative -analytic bulletin. - №№ 8, 9 .

8. Marx., Engels F. German ideology. - M.: Politizdat, 1983. - p. 29.

9. Mitroshenkov O.A. Culture and civilization // Person. Culture. Society. - M., 2003. - V. 2. - p. 219.

10. Snegovaya O.A. Globalization as a socio-cultural process. Autoabstarct of the diss. of the candidate of the philosophical sciences. - Rostov -on-Don, 2007.

11. Haydarov. R..J. The influence of the process of the globalization on the transformation of the Tajik society. Autoabstarct of the diss. Of the doctor of philosophy. - Dushanbe, 2007.

12. Orlov F.I. Social outgoings of globalization// Sociological investigation, 2001. - № 7. - C. 13 22.

13. Philosophy: Encyclopedia dictionary/ under the edition of A. A. Ivin. - Moscow: Gardarini, 2004.-1074p. http//www.ru.m.wikipedia.org (date of visit - 20.06.2016.) 